\title{
NATURE
}

\section{Young Scientists are Distinguished Too}

DISCERNING viewers were presented with a rare choice between the channels last week. ITV was showing the cliff-hanger of a soccer international between England and Poland; a match which England needed to win to proceed further in the World Cup-and did not. BBC was simultaneously showing a live programme in its Controversy series; a debate on the subject 'Soviet Scientists; a cause for concern?' In terms of action it was no contest. There was no real spirit to the rather formless debate until the last couple of minutes when Sir George Porter interrupted the reading of a quite interesting Communist apologia to substitute Sir Robert Robinson (as mistimed as Sir Alf Ramsey's substitution of $\mathrm{Mr}$ Kevin Hector at Wembley).

Nonetheless the debate, however cool and remote, did leave one clear feeling; that the British scientific hierarchy is elderly and does not convey a very lively impression of the state of British science. This remark is made in complete isolation from the question of who said what.

Even though the Royal Society did not choose to send along any of its officers, it cannot easily avoid responsibility for this state of affairs. Since it claims to be the national academy of science for the United Kingdom, it must be held ultimately responsible for the health of science, and thus for the adequate management and representation of science and scientists of all levels in both national and international affairs. This it cannot do adequately within its present framework, because it lacks anything approaching a reasonable leavening of younger scientists. This is not to deny the need for elder statesmen. It is to assert that there is an ignored and large constituency of younger men and women. These, particularly physical scientists, do their most imaginative work in the ten to fifteen years following graduation and that is the time when the best need every support that they can get, political, administrative and financial. This undoubtedly includes recognition by learned societies and most of all the Royal Society. Yet this recognition tends to come when the bloom of youth has worn off-almost as if the society waits until there cannot be a shadow of doubt that the work done is sound. Soundness seems to be a prized quality-one is reminded of the qualms of Nightingale in The Masters that Crawford might be elected to the mastership and then have his science discredited.

Anyone can have pleasant sport with the omissions from the list of fellows. Every scientist, of whatever training, seems to find plate tectonics fascinating at present, but he should not look to the fellowship for much of a discussion of it, at least at first hand. Black holes fare a little better. Inadequate representation is not a misfortune only of younger scientists. For instance, no-one seems to be a fellow by virtue of his ability to communicate science to laymen or schoolchildren or even, some may cynically say, to undergraduates. In short the society is far from being representative of the present scientific scene which is so diverse in its character. The policy-making, particularly on such issues as international collaboration, is in the hands of distinguished but at least middle-aged academics. No doubt a defence can be made that the society is greater than its fellowship in that it sponsors numerous committees and some excellent meetings, and also that many of its fellows have diverse interests and so in a sense cover the missing ground. All this is true and yet it is inescapable that at the centre of the operation of the society is the need for a representative fellowship.

What remedy is there for the inad_quacies? The Royal Society has a monopoly in speaking for British science. It chooses who and who not to have as its membership. It is unlikely that any government is going to have the time to impose any reform on it and so the pressure must come from practising scientists both inside and outside the society. It would be better if the moves came from within and it seems inescapable that the only way to reform it is to increase the fellowship substantially. There are doubtless excellent administrative reasons why the society cannot bear a substantial increase in its number, just as Oxford and Cambridge colleges have sound administrative reasons (such as a lack of suitable lavatory facilities) for not wishing to go co-educational. One hopes that discussion does not hinge on these reasons. If the backlog of worthy candidates could be reduced rapidly, more conscious efforts could be made towards creating every year at least a portion of fellows in their late twenties and early thirties. There are plenty around who would add distinction by their election.

\section{Years Ago}

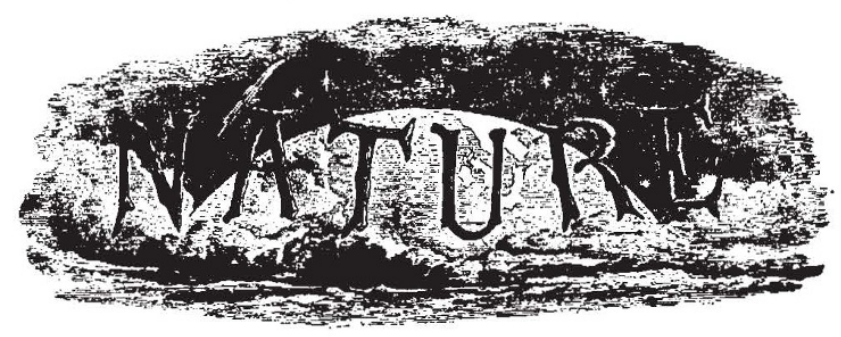

Publication of Learned Societies' Transactions

IN NATURE, vol. viii. p. $506 \mathrm{Mr}$. Röhrs wishes that our learned societies would publish their papers separately. I have urged this before in NATURE, but unsuccessfully. With rransactions such as those of the Royal Society, tine present system is almost an absurdity, for papers on most incongruous subjects are bound up together, and the cost is too great. When once a paper is printed, the Council seem to think that there is nothing more to be done, and do not in any way try to make the work known. All papers should be sold separately as cheaply as possible, and on publication, should be advertised in the scientific journals.

If this were done, we should not have men like Prof. Sylvester writing as follows :- "I owe my thanks to M. Radau and the editor of the Annals of the Ecole Normale Superieure for having been at the pains to disentomb the little known conclusions contained therein from their honourable place of sepulture in the Philosophical Transactions." W. B. GibBs

From Nature, 8, 550, October 30, 1873. 